\title{
Advantages of information and communication training at the university in the process of formation of speech competence
}

\author{
Olga Ovsyannikova ${ }^{1, *}$, Igor Bocharnikov ${ }^{2}$, and Svetlana Bobrova ${ }^{3}$ \\ ${ }^{1}$ National Security Research Center, 15 Plekhanov str., Building 2, 119571, Moscow, Russia. \\ ${ }^{2}$ Bauman Moscow State Technical University, 105005, Moscow, Central Administrative District, \\ Basmanny district, 2-ya Baumanskaya str., 5, building 1, Moscow, Russia. \\ ${ }^{3}$ Moscow State Regional University, 10A Radio str., 105005, Moscow.
}

\begin{abstract}
The developed method was tested at the Moscow State Regional University. As a result of the training and control experiments, the authors identified the advantages of information and communication training at the university in the process of forming speech competence. The analysis of the obtained data showed that in the experimental group the level of development of speech competence in the study of the morphological topic «Particle. The use of particles in speech» after the use of computer programs of the combined type created by the authors significantly increased in comparison with the results obtained in the control group. The obtained results of the training experiment make it possible to conclude that the formulated hypothesis of the study is experimentally confirmed, that is, the use of information and communication technologies in the process of studying morphology, including the topic "Particle. The use of particles in speech», is more effective if the computer program also includes a reference summary on this topic, as well as select didactic material, taking into account the typical mistakes of students. In the process of conducting a formative experiment, there is an increased interest of students in computer classes, their motivation for learning activities, and the desire to study the material. This contributes to the creation of favorable conditions for learning. The conducted training and control experiments confirmed the fact that the use of computer technologies in the educational process of the university allows us to make classes in the Russian language and speech culture more effective in the process of forming speech competence.
\end{abstract}

\section{Introduction}

It is impossible to imagine a modern higher school without the use of information and communication technologies. Computer-based learning helps to optimize and intensify the educational process, improve the teaching of all disciplines, including the Russian language and speech culture. In the learning process, the computer helps students to cope with the

\footnotetext{
*Corresponding author: mimaal@yandex.ru
} 
difficulties that are associated with the contradiction between the increasing amount of information and the real capabilities of the student, since computer technology can concentrate a significant amount of educational material, save time and effort of participants in the educational process, in a colorful, interesting and understandable form implements the principles of developmental learning developed in the works of $\mathrm{V}$. V. Davydov [1], L.S.Vygotsky [2] and others.

Information and communication technologies activate the cognitive activity of students. Computer-based learning is one of the most promising areas of modern teaching methods. Rational use of the computer in the classroom allows students to productively reveal such a section of the Russian language as morphology, that is, the basis on which all other sections are based.

The study of the Russian language and speech culture with computer support was carried out by such researchers as N. N. Algazina, I. Yu. Gats, E. S. Antonova [3] and others. They created, methodically justified and tested training programs in various sections of the science of language, as well as presented a methodology for conducting classes using a computer when teaching certain topics.

The research is based on the works on linguistics of V. V. Vinogradov [4], A. M. Peshkovsky [5], on the issues of pedagogy and psychology of the Russian Academy of Sciences I.Galperina, N. F.Talyzina [6], according to the methodology of the Russian language by A.V. Dudnikov [7], on computer training by B. S. Gershunsky [8], E.I.Mashbits [9] and others.

\section{Methods}

The developed method was tested at the Moscow State Regional University.

The methodological apparatus of the study was presented by the following methods:

- general scientific: analysis and synthesis, abstraction and generalization, induction, deduction, analogy, as well as system, structural and functional, probabilistic;

- theoretical scientific methods: system-level, historical-epistemological, theoreticalanalytical and functional-research analysis of existing ideas on the research problem, content analysis of scientific literature; the method of thought experiment, idealization and formalization, axiomatic method;

- the method of collecting empirical data (testing, questioning, direct, indirect, included observation, conversation, interview, experiment);

- praximetric (analysis of the products of students ' activities);

- constructive and interpretative methods (quantitative and qualitative assessment of the relationship between objective parameters; statistical and mathematical processing of the initial data and the results of the experiment).

The main method of research was the ascertaining and forming experiments. The objectives of the ascertaining experiment were:

- to establish the degree of completeness and strength of knowledge on the topic «Particle as a service part of speech. Particle consumption»;

- identification and grouping of typical mistakes made by students in sentences and texts;

- finding out the level of mastery of the skills to distinguish particles by their meaning, to determine the categories, to use in speech.

The results of the ascertaining experiment allowed us to trace how firmly the knowledge on the topic «Particle. The use of particles in speech», whether skills and abilities were formed on their basis. 60 first-year students took part in this ascertaining and forming experiment. During the experiments, students were asked to perform cross-section work, which consisted of 10 tasks. The specifics of these works were determined by the tasks of 
the experiment. When selecting didactic material, the requirements of the program, the principle of concentration of the studied language phenomena were taken into account, difficult cases were taken into account. It was proposed to define this part of speech in sentences and texts, to distinguish different categories of particles, namely: modal, formative and negative particles. It was necessary to specify their meanings in the sentences, to make a morphological analysis of the particles, as well as to make sentences or a small text.

Then the students of the control group (30 people) studied these topics, without using a computer program, according to the traditional method, and the students of the experimental group (30 people) studied these topics using a computer program compiled according to the created scenarios. The obtained results were compared with the levels of formation of these skills and abilities.

\section{Results}

In the experimental group, in which students studied this topic using computer technology, the results are much better than in the control group. The data obtained in the course of the study can be commented on certain topics.

We will compare the data of the test work that was carried out in the experimental and control groups after studying the topics.

Before studying the topic, students were offered a task, according to the results of which it was possible to conclude whether the students have knowledge on this topic, whether they are able to find this part of speech in the text. The following results were obtained, which are clearly presented in the diagram. (Fig. 1). Out of 60 students, only 18 people $(26.7 \%)$ correctly identified all the particles, 27 students $(56.7 \%)$ did not correctly indicate all the particles in the text, and 15 students $(16.6 \%)$ did not cope with the work.
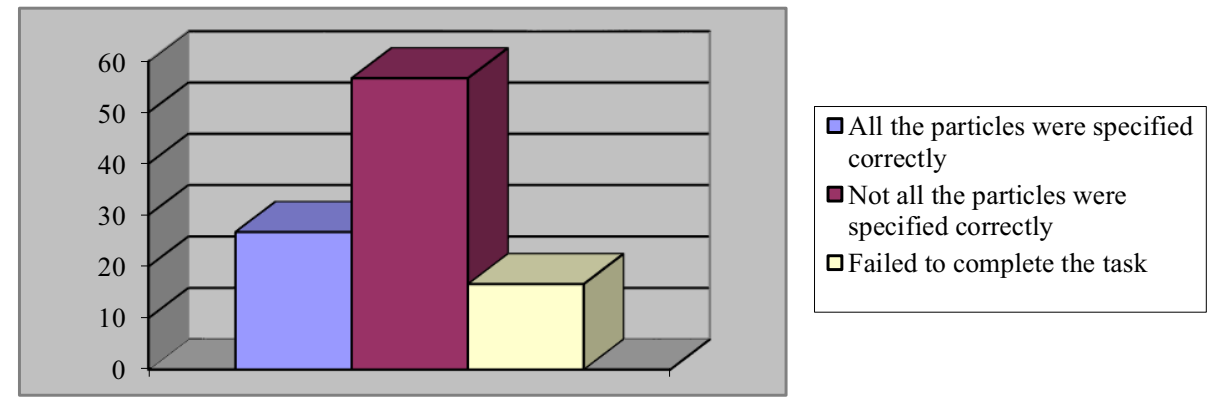

Fig. 1. Data from the test work before studying the topic.

The data of the test work before studying the topic indicate that students have only a superficial knowledge of this topic, which was preserved after studying the school course of the Russian language. It should be noted that in the course of performing the test work, students made the following mistakes:

1. In certain sentences, all the particles are not highlighted ( 8 people $-26.7 \%$ ).

2. The greatest number of mistakes made by students when distinguishing between particles and homonymous parts of speech ( 9 people $-30 \%)$.

3. Students were not allocated the entire particle, but only part of it, for example: hardly, scarcely $(6-20 \%)$.

4. Particles counted the words of other parts of speech, for example: Yes, (the Union), it (pronoun), something (pronoun) $-(7-23,3 \%)$. The results of the test task are clearly shown in the diagram (Fig. 2). 


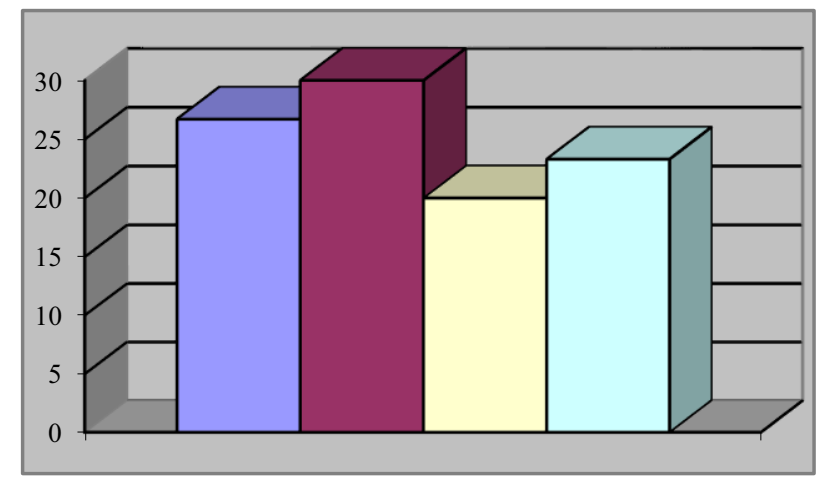

口Selection of not all particles

口Errors in delineation

口Incompleteness of particle selection

口Mixing parts of speech

Fig. 2. Typical errors during the task execution.

It is necessary to analyze the results of the task in the experimental and control groups after studying this topic with the use of computer programs and without them.

All students coped with this task and received a positive result, but a higher level of performance is observed in the experimental group, as can be seen from Table 1 and the diagram (Fig. 3).

Table 1. Results of the task in the experimental and control groups.

\begin{tabular}{|l|c|c|c|}
\hline \multirow{2}{*}{$\begin{array}{c}\text { Groups of } \\
\text { students }\end{array}$} & \multicolumn{3}{|c|}{ \% of students who completed the task } \\
\cline { 2 - 4 } & High level & Medium level & Low level \\
\hline Experimental & $46 \%$ & $41 \%$ & $13 \%$ \\
\hline Control & $34 \%$ & $35 \%$ & $21 \%$ \\
\hline
\end{tabular}

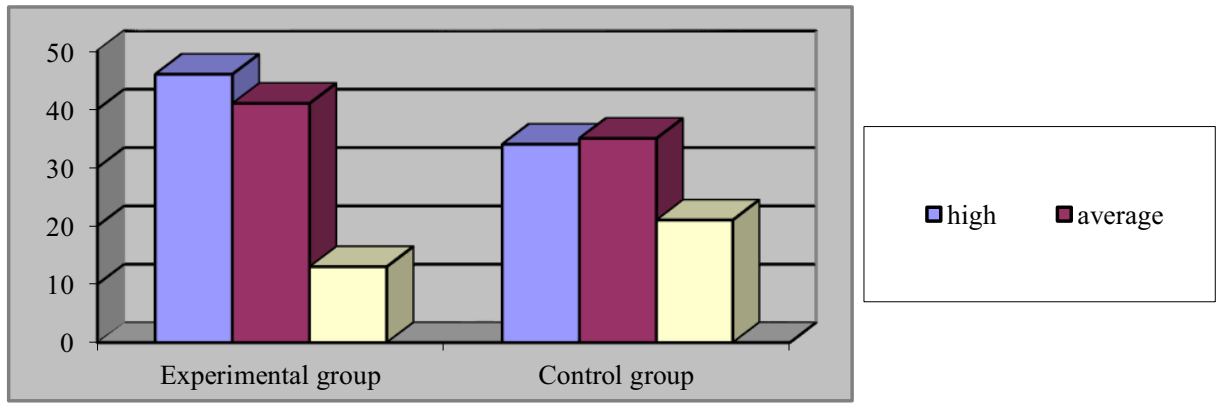

Fig. 3. Results of the task in the experimental and control groups.

It should be noted that the students of the control group made the following mistakes when completing the task:

1. No particles were identified, such as oh, yes, just others ( 8 people $-37.5 \%)$.

2. In several sentences, instead of particles, the students ( 7 people $-23.3 \%)$ designated and (union), all (pronoun) in the sentence, and others.

In the experimental group, the results of performing the same task are better than in the control group, as can be seen from Table 1 and Figure 3.

However, the mistakes made in these tasks are much smaller. Some students ( 8 people $26.6 \%$ ) did not select the particles hardly, exclusively, and, yes, which present a certain difficulty in the sentences. In these works, 2 errors $(6 \%)$ were made for mixing particles with words of other parts of speech, which indicates the effectiveness of this computer program. 


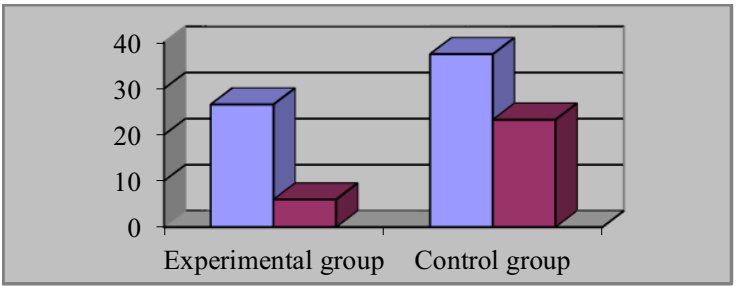

口Skipping particles

口Mixing errors

Fig. 4. Typical errors when performing the task in the experimental and control groups.

\section{Discussion}

The data of the training experiment indicate the effectiveness and expediency of using information and communication technologies in teaching the Russian language and speech culture, in particular in the study of such a service part of speech as a particle.

In the process of conducting a formative experiment, there is an increased interest of students in computer classes, their motivation for learning activities, and a desire to study the material. This contributes to the creation of favorable conditions for learning. After the end of the experiment, students were asked to list the advantages of computer-assisted classes. (Did you enjoy the computer classes and why?). Students noted the reasons for their interest in the use of information and communication technologies:

- more interesting than in regular classes $-78 \%$;

- no need to take notes $-81 \%$;

- you can quickly find and fix the error $-93 \%$;

- there is time to think about the answer $-95 \%$;

- it is possible to return to the material where the difficulty occurred $-63 \%$.

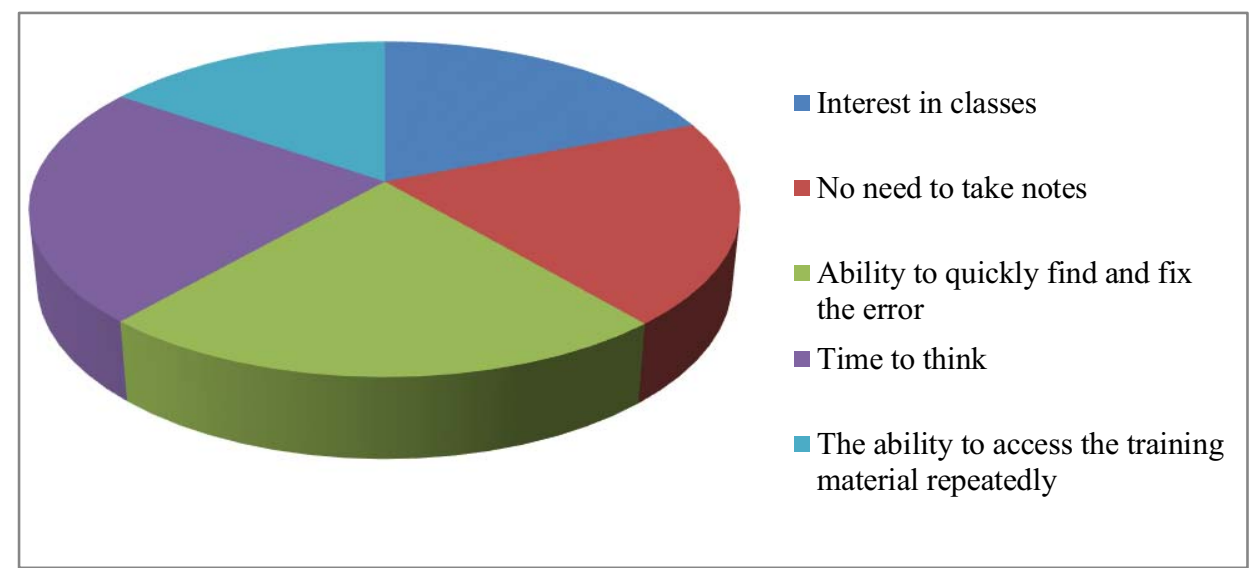

Fig. 5. Reasons for interest in the use of information and communication technologies.

It should be noted that the point of view of students coincides with the opinion of teachers that one of the main advantages of computer-based learning is the individualization of the educational process. The obtained results of the training experiment make it possible to conclude that the formulated hypothesis of the study is experimentally confirmed, that is, the use of information and communication technologies in the process of studying morphology, including the topic «Particle. The use of particles in speech», is more effective if the computer program includes a reference summary on this topic, as well as select didactic material, taking into account the typical mistakes of students. 
The conducted training and control experiments confirmed the fact that the use of computer technologies in the educational process allows us to make classes in the Russian language and speech culture more effective, since:

- the time saved during the execution of tasks increases the volume and number of tasks aimed at fixing the material;

- the use of diagrams and reference notes allows each student to present, for example, a particle as a part of speech in all its diversity, taking into account semantic connections and relations with certain units of the language.;

- scenarios for computer classes allow you to take into account the previous training material already passed and thus, in parallel with the new information, fill in certain gaps in the knowledge of each student, since the computer program allows you to study new material in an individual mode;

- the computer as a means of learning is indispensable in the application of knowledge, as it primarily forms the correct way of acting with the particle;

- the computer is used as a multifunctional visual aid with huge possibilities for the presentation of various educational materials;

- the computer contributes to the organization of differentiated training, when the strength of the developed skill and skill depends on taking into account the individual difficulties of each student, on the volume and options of the analyzed examples.

\section{Conclusions}

The use of information and communication technologies makes it possible to perform a larger volume and number of tasks, students can concentrate more carefully on the task, that is, not be distracted by taking notes of educational material and suggestions from tasks, analyze the responses of other students, perform tasks at an acceptable individual pace for them. In addition, the computer removes the situation of psychological stress that occurs in the case of an incorrect response of the student in the process of collective work. All these objective and subjective factors allow us to explain the higher results of mastering the topic in the experimental groups. The results of the study demonstrate that the absolute advantage of the computer is the possibility of the greatest differentiation of the learning process, as well as the implementation of differentiated training, when each student has the opportunity to focus on exactly what his difficulties are associated with, in other words, has the ability to cope with their own learning problems, and not with the problems of the whole group.

It should also be noted that after the training experiment, students showed an increased interest in classes in the Russian language and speech culture, increased motivation and reflection of speech behavior, their desire to explore the educational material, and not just memorize it, which contributes to the creation of favorable conditions for learning. Students became interested in the final result, namely, in the acquired speech and language knowledge and skills, which increases cognitive activity and, consequently, the effectiveness of learning.

In other words, information and communication technologies open up opportunities for the implementation of the most modern methods and techniques in the educational process and therefore increase its effectiveness, including in the process of formation and development of speech competence.

The presented research is of practical significance for specialists and teachers who are engaged in the development of the problem of the use of information and communication technologies in the learning process. The results obtained in the course of the study will help teachers to implement these technologies efficiently and correctly. The prospects of the research are to further study and create a variety of courses and individual topics in this discipline. 
The use of information and communication technologies meets the principles of developmental learning, develops language reflection and motivation, which is the basis of the student's self-assessment.

The characteristic features of computer-based learning of the Russian language in the process of formation and development of speech competence are the individualization of the educational process, a large amount of independent work of students, feedback, which is so necessary and relevant in the context of distance learning, in connection with the current situation.

\section{References}

1. V.V. Davydov, Questions of psychology 6, 3-13 (1991)

2. L.S. Vygotsky, Pedagogical psychology (Moscow, Pedagogika, 1991)

3. N.N. Algazina, G.A. Fomicheva, E.S. Antonova, I.Yu. Gats, Methods of teaching the Russian language. A short summary of lectures. Part 1 (Moscow, 1997)

4. V.V. Vinogradov, Russian language (Grammatical teaching about the word): A textbook for universities (Moscow, Higher School, 1986)

5. A.M. Peshkovsky, Selected works (Moscow, Uchpedgiz, 1959)

6. P.Ya. Galperin, Z.A. Reshetova, N.F. Talyzina, Psychological and pedagogical problems of programmed learning at the present stage (M., 1966)

7. A.V. Dudnikov, Modern Russian language: Textbook for philologists special universities of the Union and Autonomous Republics (Moscow, Vysshaya Shkola, 1990)

8. B.S. Gershunsky, Computerization in the field of education: problems and prospects (Moscow, Pedagogika, 1984)

9. E.I. Mashbits, Psychological and pedagogical problems of computerization of education (Moscow, Pedagogika, 1988)

10. State Program Digital Economy of the Russian Federation dated July 28, 2017 No. 1632-r, https://government.ru/2006/07/29/informacia-dok.html

11. O.A. Ovsyannikova, S.V. Bobrova, I.V. Bocharnikov, E3S Web of Conferences. VIII International Scientific and Practical Conference "Innovative technologies in science and education» (ITSE 2020) (2020)

12. O.A. Ovsyannikova, M.A. Mishcherina, I.V. Bocharnikov, E3S Web of Conferences. VIII International Scientific and Practical Conference "Innovative technologies in science and education» (ITSE 2020) (2020)

13. I.V. Bocharnikov, Bulletin of the Moscow State Humanitarian and Economic Institute 1(13), 71-75 (2013)

14. O.A. Ovsyannikova, Optimization of the process of studying particles with computer support: dis. ... kand.ped. nauk (Moscow, 2003)

15. E.M. Markova, J.V. Bobrova, S.V., Mishcherina, Technologies for the development of speech-thinking abilities of schoolchildren in the process of learning the Russian language. I caught up (Brno, 2014) 